Shuvo, B.D. and Lu, M. 2020. "Lean Construction Planning subject to Variations in detailed Features of Fabricated Bridge Girders.” In: Tommelein, I.D. and Daniel, E. (eds.). Proc. $28^{\text {th }}$ Annual Conference of the International Group for Lean Construction (IGLC28), Berkeley, California, USA, doi.org/10.24928/2020/0115, online at iglc.net.

\title{
LEAN CONSTRUCTION PLANNING SUBJECT TO VARIATIONS IN DETAILED FEATURES OF FABRICATED BRIDGE GIRDERS
}

\author{
Badhon Das Shuvo ${ }^{1}$ and Ming Lu ${ }^{2}$
}

\begin{abstract}
With the growing implementation of prefabrication and off-site construction in practice, the focus of job shop scheduling shifts from manufacturing to the practical application context in construction. This research explores a new lean approach to project planning and scheduling assisted with production operations planning by simulation. The research methodology uses a simulation model that had been developed to account for sufficient details from the perspective of the actual shop manager and thoroughly validated in collaboration with an industry partner. A simulation case of planning bridge girder fabrication at a steel fabrication shop was conducted to illuminate on 'mura' (variations in product design and production process) inherent in girder fabrication. Based on the simulation, we made an attempt to elaborate the inherent variations in girder fabrication time and inter-girder lag in order to facilitate applying lean concepts in planning bridge construction projects.
\end{abstract}

\section{KEYWORDS}

Variations, collaboration, fabrication, waste, reliable

\section{INTRODUCTION}

Offsite construction (such as prefabrication, pre-assembly, or modularization) has been practiced widely for decades in the construction industry in pursuit of realizing the lower cost, tighter schedules, higher resource use efficiency, and ultimately, productivity improvement. Nonetheless, to produce structural components of similar types in executing precast and prefabrication projects, variations in design features and fabrication processes result in one-of-a-kind jobs and add to the complexity in project planning. Without acknowledging these variations that could potentially multiply uncertainties in resource utilization and work processes in the process of production planning, it would result in significant errors in the project schedule and cost budget. This would also present a distinctive challenge in delivering predictable project performances and making it difficult to reduce cost overruns, delays, and disputes between different parties (Tzortzopoulos and Formoso 1999, Dosumu and Aigbavboa 2017).

1 MSc Student, Civil and Environmental Engineering Department, University of Alberta, Canada, +1 780 485-7681, badhonda@ualberta.ca, orcid.org/0000-0002-5396-196X

2 Professor, Civil and Environmental Engineering Department, University of Alberta, Canada, +1780 492-5110, mlu6@ualberta.ca, orcid.org/0000-0002-8191-8627 
The lean philosophy was developed aiming at the removal of 'muda' (the waste in material, time and space) (Womack and Jones 1997) through systematic planning; however, if the existence of ' $m u r a$ ' (variations in product design and production process) (Shingo and Dillon 1989) is not well understood and even ignored in planning and scheduling, muda would be impossible to be controlled, let alone to be reduced or eliminated. For this reason, this paper uses a real-world case of planning bridge girder fabrication at a steel fabrication shop to illuminate on the above-identified problem. It is worth mentioning that in a separate, recent endeavor, a computer simulation model had been developed to account for sufficient details from the perspective of the actual shop manager and thoroughly validated in conjunction with an industry partner (Hasan et al. 2019). The resulting simulation model provides a reliable and convenient vehicle for the present research to design "what-if" scenarios for simulation and collect simulation data as if they would have been the consequences from executing a postulated scenario in the fabrication shop being studied. An in-depth analysis of the simulation model reveals the mura inherent in girder design and fabrication processes, which is especially instrumental in planning lean processes for girder shipment, storage, and installation in the field aimed at minimizing the muda waste (such as renting extra laydown yard in the field or idling installation crew in the field due to waiting for girder delivery).

The current practice of project planning and scheduling generally uses MS Projects or P6 to generate a precedence diagram schedule without accounting for the impact of variations in girder design and fabrication process upon fabrication time and logic, ultimately causing significant ' $m u d a$ ' waste in girder storage, shipment and field installation. In this research, we take advantage of a validated simulation model for a structural component fabrication shop in the service of construction projects. The simulation model was developed and validated in Hasan et al. (2019), which serves as the virtual plant for a bridge girder fabrication shop in the real world. In the case study, insights gained from the virtual plant in regards to girder fabrication time and start-tostart lag time between consecutive girders are extracted and further generalized as planning guidelines for project schedulers.

\section{LITERATURE REVIEW}

Project complexity influences project planning, coordination, and control criteria, impedes clear identification of major project goals and objectives, influences the selection of project inputs, affects the project objectives related to scope, time, expense, and quality (Baccarini 1996). The complexity of each project, unpredictability of project time, and lack of detailed planning are identified as key factors for rework and possibly schedule resequencing, acceleration, delay, or suspension (Tommelein 1997, Ibbs 2012). Job shop scheduling problems (JSSP) are considered "one of the hardest combinatorial optimization problems" (Lawler et al. 1982); over the past few decades, numerous algorithms have been developed for solving JSSP defined in the manufacturing sector. Manufacturing processes generally involve a lesser amount of resource-constrained relationships between activities, where the variation in different pieces of a product is insignificant ( $\mathrm{Lu}$ and Wong 2007). In contrast with manufacturing, construction is a project-oriented business endeavor producing unique products, where more resources are involved; more interrelationships exist between activities due to space, resource, and technology constraints (Ortega and Bisgaard 2002, Lu and Wong 2007). With the growing implementation of prefabrication and off-site construction in practice, the focus of job shop scheduling shifts from manufacturing to the practical application context in 
construction. A fabrication shop servicing construction projects produces made-to-order products featuring significant variations in product details, fabrication processes, and required shop processing times due to limited resource availability constraints (e.g., shared crane, shared workspace, and shared journeymen). In addition, the size and weight for the product are large and heavy, making it not flexible and not safe to move them around and store them at temporary storage or laydown place in and out of the shop. JSSP also becomes a very important practical planning problem in a construction system, which makes it increasingly important to explore ways of obtaining better solutions to produce an efficient and acceptable schedule in time (Adams et al. 1988).

At present, the performance of the construction industry still remains low, and productivity improvement is marginal in comparison with other industries (Sacks and Goldin 2007). Well established algorithms to solve JSSP assume production processes behave linearly in most cases (Arisha et al. 2001). Nonetheless, some or most of the constraints in a fabrication facility that makes structural components specifically for construction projects cannot be represented as linear as in manufacturing. Taking structural steel fabrication, for example, scheduling operations at offsite production facilities often pose unique constraints due to one-of-a-kind product design, simultaneous execution of multiple projects, and limited skilled trades and space available in a fabrication shop, which is not much different from planning the construction activities in the field (Liu and Lu, 2018). New technologies (such as offsite prefabrication and modular construction) have yet to materialize promised benefits in terms of reducing design and construction costs while improving efficiency and productivity in construction processes (Aziz and Hafez 2013). Furthermore, most companies find it insufficient to implement mainstream project scheduling techniques in support of planning their prefabrication projects.

Simulation keeps track of the changes of the state of a system occurring at discrete points of time and builds a logical model of a system for experimenting on a computer and providing users with insight into the system's resource application, interactions, and constraints (Pidd 1998). Hence, developing a detailed simulation model is warranted in order to account for varying design features and different workflows throughout the fabrication process. It is noteworthy these variations exist in reality, are clearly specified in the production plan, and exert significant influence upon time duration in making a girder and the lag time between the start times of processing consecutive girders at the fabrication shop. Such variations cannot be overlooked; instead, they need to be analytically modeled and predicted by proper production planning (Hasan et al. 2019). The remainder of the paper resorts to a case study of bridge girder fabrication to further investigate the simulation model for a bridge girder fabrication shop of our industry partner (Hasan et al. 2019). Based on the simulation, we make an attempt to elaborate on the effect of variations due to product design and workflows in girder fabrication in the context of applying lean concepts for planning field construction operations in practice.

\section{CASE STUDY}

\section{BRIDGE GIRDER FABRICATION}

Planning and scheduling operations at the steel fabrication shop pose distinctive challenges due to one-of-a-kind girder design, multi-project simultaneous execution, and limited limits of the available skilled trades (Song and Abourizk 2003). Each girder piece is alike in appearance but is indeed a unique structural component with special features 
(such as shop splice, field splice, stiffeners, studs, number of drill holes, weld thickness, etc.). These features play a vital role in determining the specification of work package layout and processing sequences for each girder to go through the shop floor workstations. Figure 1 shows (a) the setting of a typical bridge girder fabrication shop and (b) structural steel girders underneath a built bridge.

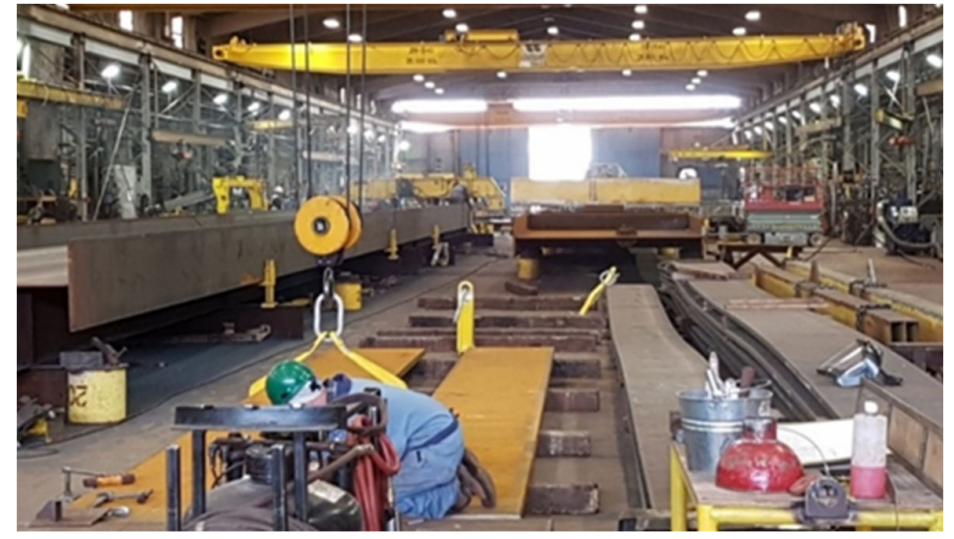

(a)

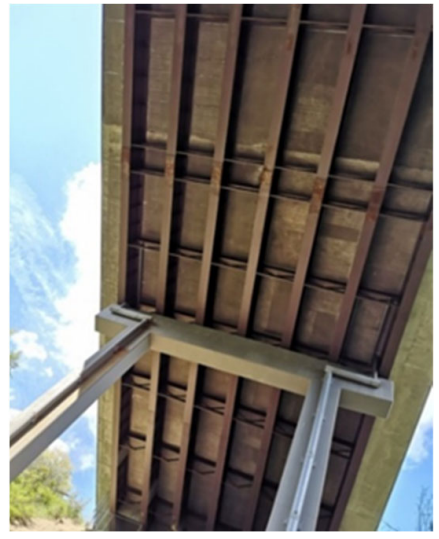

(b)

Figure 1: (a) setting of a typical bridge girder fabrication shop

(b) structural steel girders underneath a built bridge

The case study was conducted based on a steel bridge fabrication shop located at Alberta; the scope of production planning consists of 15 girders that make up five girder lines for a bridge project. The girders have been classified into four categories (Type 1- 4) based on their design attributes (length, depth, shop splices, field splices, stiffener quantity and locations). Table 1 summarizes the girders' attributes defining a unique type of girder, and their structural design variations, which is defined in the simulation model developed for the bridge girder fabrication shop being studied (Hasan et al. 2019).

Table 1: Properties of different girder types of the case study

\begin{tabular}{ccccccc}
\hline Type & $\begin{array}{c}\text { Length of } \\
\text { the girderl } \\
\text { flanges/ } \\
\text { web-plate }\end{array}$ & $\begin{array}{c}\text { Number of } \\
\text { the field } \\
\text { splices }\end{array}$ & $\begin{array}{c}\text { Number of } \\
\text { flange } \\
\text { splices }\end{array}$ & $\begin{array}{c}\text { Number } \\
\text { of web } \\
\text { plates }\end{array}$ & $\begin{array}{c}\text { Stiffener } \\
\text { complexity }\end{array}$ & $\begin{array}{c}\text { Stiffener } \\
\text { welding } \\
\text { complexity }\end{array}$ \\
\hline 1 & $24 \mathrm{~m}$ & 1 & 0 & 1 & 1 & 1 \\
2 & $32 \mathrm{~m}$ & 2 & 1 & 2 & 1 & 1 \\
3 & $24 \mathrm{~m}$ & 1 & 0 & 1 & 1.5 & 1.5 \\
4 & $32 \mathrm{~m}$ & 2 & 1 & 2 & 1.5 & 1.5 \\
\hline
\end{tabular}

The four types of girder share some identical features among them (e.g. width of the flanges and web plates, thickness of the flanges and web plates, number of holes in one end of the flange, girder shape complexity etc.). Aside from these similarities, numerous variations among them are notable. Type 1 and Type 3 have the same length of the girder $(24 \mathrm{~m})$, flanges and web-plates, have one field splices on one end of the girder, zero flange splices and one web-plate, whereas Type 2 and Type 4 share similar attributes between them. The length of the girder, flanges and web-plates vary based on the geometrical 
dimension as per structural design. The number of field splices $\left(\mathrm{N}_{\mathrm{F}}\right)$ is dependent on the number of girders in the girder line. If there is one girder in the girder line, $\mathrm{N}_{\mathrm{F}}$ is 0 ; if there are multiple girders and the subject girder is the abutment side girder, $\mathrm{N}_{\mathrm{F}}$ becomes 1 , and if the subject girder is the middle one with two girders at each end, $N_{F}$ equals 2.

Besides, the number of flange splices is dependent on the ratio of the girder length to the flange plate length; whereas the number of web-plates varies based on the ratio of the girder length to the web plate length. Irrespective of these attributes, Type 1 is distinguished from Type 3 in terms of stiffener complexity and welding complexity, but shares the same properties with Type 2; whereas Type 3 shares these attributes with Type 4. The stiffener complexity varies based on the relative features of a particular girder type against the standard girder configuration; whereas the welding complexity depends on the angle between the web and stiffeners (a factor of 1 stands for 90 degree, 1.5 for 45 degree, and 2 for other cases). These variations are due to their structural design and their relative features against the specific features of the standard girder. Figure 2 illustrates some detailed features relevant to girder type definition in bridge girder fabrication.

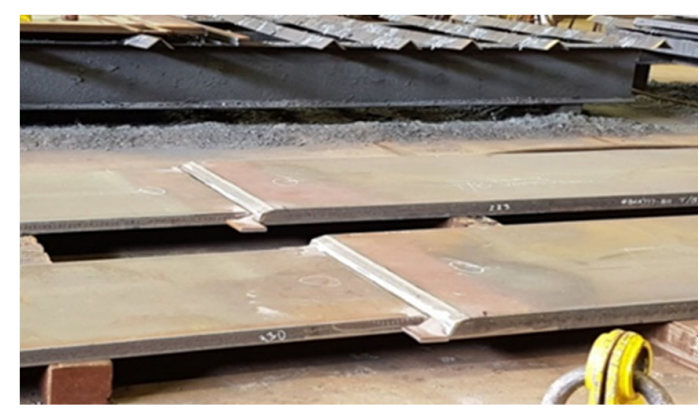

(a) Flange Splice

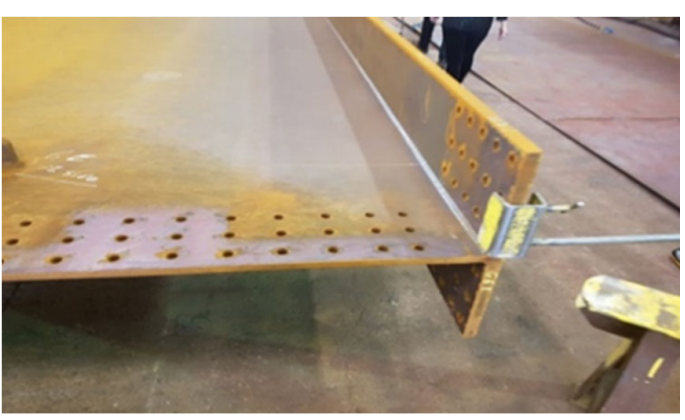

(c) End Holes for Field Splice

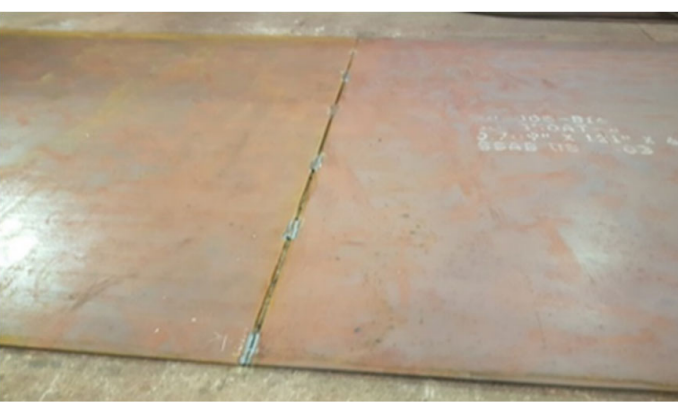

(b) Web Splice

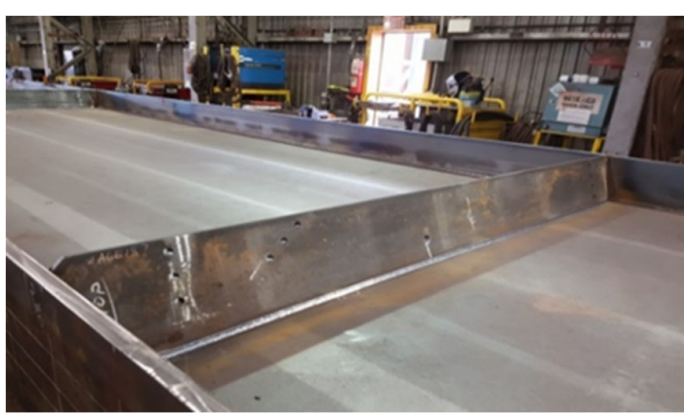

(d) Stiffener

Figure 2: Detailed features relevant to girder type definition in bridge girder fabrication

The scope of the simulation study is to model detailed workflows in fabrication of girders for a highway bridge at a bridge girder fabrication shop. The project entails the fabrication of a total of 15 girders, making up five girder lines (GL1, GL2, GL3, GL4, and GL5) for a bridge project. Three girders are connected along each girder line to form the bridge span. Raw materials required for the fabrication of girder are structural steel plates. Steel fabrication produces steel components and converts steel plates into girders in the constrained space of the fabrication shop and as per shop drawings and engineering design. The fabrication operation consists primarily of the following major steps: (1) receiving plates, (2) preparation of flanges, (3) preparation of web and (4) preparation stiffener, (5) girder assembling by fitting and welding flanges to web, (6) stiffener fitting and welding, 
(7) studding, (8) field splicing, (9) sandblasting and finishing. Description of detailed processes and work flows for different girder types can be found in Hasan et al. (2019).

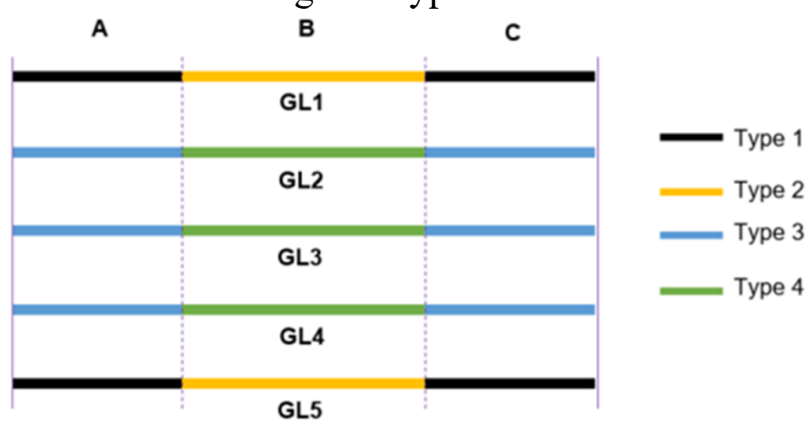

Figure 3: Schematic diagram of the girder lines

Table 2: Classification of girders into four types

\begin{tabular}{ccccc}
\hline Type of Girder & Type 1 & Type 2 & Type 3 & Type 4 \\
\hline Girders & $\begin{array}{c}\text { GL1A, GL1C, } \\
\text { GL5A, GL5C }\end{array}$ & GL1B, GL5B & $\begin{array}{l}\text { GL2A, GL2C, } \\
\text { GL3A, GL3C, } \\
\text { GL4A, GL4C }\end{array}$ & $\begin{array}{c}\text { GL2B, GL3B, } \\
\text { GL4B }\end{array}$ \\
\hline Symbol & $\bigcirc$ & $\square$ & $\triangle$ & $\nabla$ \\
\hline
\end{tabular}

Different symbols have been assigned to each girder type, and specific girders under each type are shown in Table 2. In short, given two girders, the structural design parameters such as web or flange dimensions, load capacity can be the same, but fabrication features would make each girder one of a kind. Detailed features of the products differentiate the steel fabrication process and ensuing field installation method from typical manufacturing where identical products are produced in a predominantly linear process in mass quantities. To a certain degree, it is difficult for a project scheduler to sufficiently account for the impact of subtle variations in product design and fabrications processes at the time of planning or scheduling and thus pulls off lean application in construction. As a matter of fact, a valid simulation model of the fabrication shop that has considered all the relevant variations in girder fabrication potentially provides a virtual plant for planning and scheduling girder fabrication, shipment, field installation for the bridge project. In short, this study explores a new lean approach to project planning and scheduling assisted with production operations planning by simulation.

\section{Planning And Scheduling}

In the simulation case study, shop floor operations follow the sequence of fabricating all the girder lines subject to resource availability constraints (such as finite quantities of laborers and workstations) and in line with the proposed field construction plan (i.e. GL 1, GL 2, GL 3, GL 4, GL 5) as shown in Figure 4. 


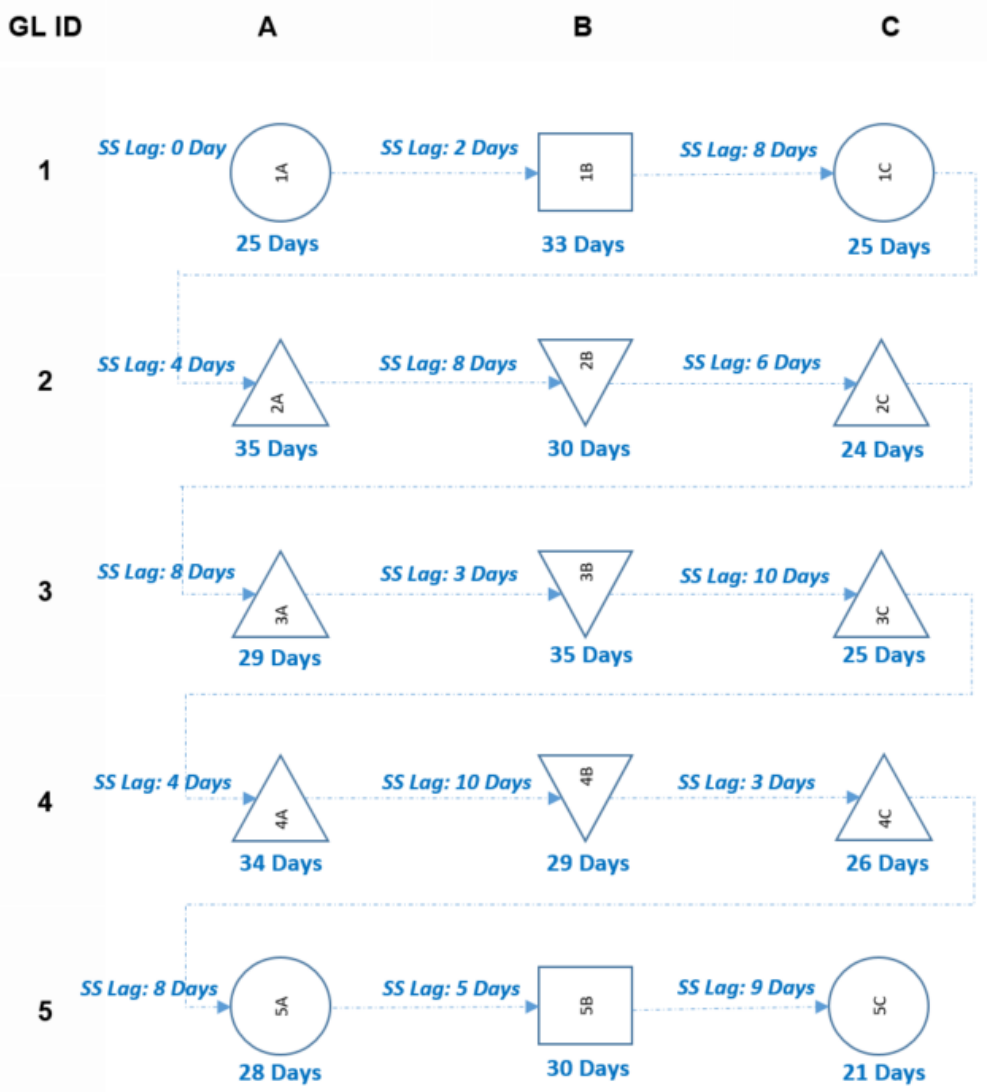

Figure 4: Start and finish schedule for the case study project (girder by girder)

Hasan et al. (2019) formalized the methodology for implementing the Simplified Discrete-Event Simulation Approach (SDESA) in this application domain; the resulting SDESA model mimics the common practice of using CPM in construction planning but requires much less effort in modeling construction operations to adequately represent girder type-dependent workflows and resource transfer ( $\mathrm{Lu}$ et al. 2009). An SDESA model normally contains (1) a process model for describing jobs (flow entities), activities, precedence relationships, resource requirements, and any logical constraints, (2) a resource pool for holding all resource entities provided, and (3) a resource transit information system for modeling the additional state changes (if any) of the system due to resource transit between activity locations (Lu and Wong 2007). Due to size limit, refer to Hasan et al. (2019) for the elaboration of SDESA fabrication shop model development and validation. Herein, the results from the SDESA model are extracted and further analyzed in support of a project planner to implementing lean construction in regards to predicting girder fabrication duration for just-in-time shipment to the field for erection.

In contrast with the current scheduling practice in platforms like MS Project, Primavera P6 (defining activity predecessor relationship one by one, and estimating activity duration or lag times), the girder production schedule is "automatically" generated by detailed aggregating data resulting from the shop production planning simulation model in SDESA. It is clarified in this simulation application; the SDESA sets most likely values on input variables in the simulation model to derive deterministic results representing the time duration of each girder of a particular type and the start-tostart lag time between girders of different types. According to the girder-fabrication 
schedule from simulation, multiple girders (maximum 5 girders) can be processed concurrently at any given moment in the shop. This had been validated by the experienced shop manager who has a good grasp of the shop production capacity. As shown in Figure 4 , the shop fabrication duration for each girder (in workdays) and the start-to-start (SS) lag time between two consecutive girders in the present case study is derived from SDESA simulation.

\section{OBSERVATION AND DISCUSSION}

In current project planning and scheduling practice, we assume (1) all girders of the same type have same time duration for shop fabrication and (2) the SS lag linking two girders of specific types is a constant. The results from the simulation model shows notable variations on fabrication duration (Table 3) and SS lags given two girders of the same type combination (Table 4). Table 3 shows the start and finish fabrication time of each girder as well as the duration in days required to fabricate each girder resulting from simulation. In terms of girder lines, each girder line also needs different number of days to be completed. GL 1 takes 36 days, GL 2 and 3 each take 38 days, GL 4 takes 39 days, while GL 5 finishes in 35 Days. It is observed not only girders of different types have different duration, but the girders of same type also can take different duration. For example, the duration to complete the Type 2 girders ( 33 days, and 30 days) is in contrast with the number of days it takes for the completion of Type 3 girders ( 35 days, 24 days, 29 days, 25 days, 34 days, and 26 days). If we consider the same type of girders, for example, the different girders under Type 3 (GL2A, GL2C, GL3A, GL3C, GL4A, GL4C), there is also a notable variation in fabrication duration (35 days, 24 days, 29 days, 25 days, 34 days, and 26 days).

Table 3: Start and finish fabrication time of each girder

\begin{tabular}{|c|c|c|c|c|}
\hline Girder Type & Girder ID & $\begin{array}{l}\text { Start } \\
\text { (D-M) }\end{array}$ & $\begin{array}{l}\text { Finish } \\
\text { (D-M) }\end{array}$ & $\begin{array}{c}\text { Duration } \\
\text { (Days) }\end{array}$ \\
\hline \multirow{4}{*}{0} & $1 \mathrm{~A}$ & 01-Apr & 26-Apr & 25 \\
\hline & $1 \mathrm{C}$ & 11-Apr & 06-May & 25 \\
\hline & $5 A$ & 14-Jun & 12-Jul & 28 \\
\hline & $5 C$ & 28-Jun & 19-Jul & 21 \\
\hline \multirow{2}{*}{$\square$} & 1B & 03-Apr & 06-May & 33 \\
\hline & $5 B$ & 19-Jun & 19-Jul & 30 \\
\hline \multirow{6}{*}{$\triangle$} & $2 \mathrm{~A}$ & 15-Apr & 20-May & 35 \\
\hline & $2 \mathrm{C}$ & 29-Apr & 23-May & 24 \\
\hline & $3 A$ & 07-May & 05-Jun & 29 \\
\hline & $3 C$ & 20-May & 14-Jun & 25 \\
\hline & $4 \mathrm{~A}$ & 24-May & 27-Jun & 34 \\
\hline & $4 C$ & 06-Jun & 02-Jul & 26 \\
\hline \multirow{3}{*}{$\nabla$} & $2 B$ & 23-Apr & 23-May & 30 \\
\hline & $3 B$ & 10-May & 14-Jun & 35 \\
\hline & 4B & 03-Jun & 02-Jul & 29 \\
\hline
\end{tabular}

In addition to the individual girder fabrication duration, the SS lag time between two different types is the other critical piece of input information to develop the project schedule for bridge fabrication and installation. In SDESA, the lag times were calculated from the delay between the start of two activities (Table 3) to establish a Start-to-Start 
(SS) dependency. Table 4 shows the variations in the SS lag times between two different types of girders, which can be attributed to variations in product design and fabrication processes.

Table 4: SS lag times (days) between two different types of girders

\begin{tabular}{|c|c|c|c|}
\hline $\begin{array}{l}\text { Girder Type } \\
\text { Combination }\end{array}$ & Remarks & Instances & $\begin{array}{l}\text { Lag Time } \\
\text { (Days) }\end{array}$ \\
\hline & \multirow{2}{*}{$\begin{array}{l}\text { Type } 1 \text { girder precedes Type } 2 \text { girder with SS lag } \\
\text { time }\end{array}$} & $1 \mathrm{~A}-1 \mathrm{~B}$ & 2 \\
\hline & & $5 A-5 B$ & 5 \\
\hline & \multirow{2}{*}{$\begin{array}{l}\text { Type } 2 \text { girder precedes Type } 1 \text { girder with SS lag } \\
\text { time }\end{array}$} & $2 B-2 C$ & 8 \\
\hline & & $5 B-5 C$ & 9 \\
\hline$O \rightarrow$ & $\begin{array}{l}\text { Type } 1 \text { girder precedes Type } 3 \text { girder with SS lag } \\
\text { time }\end{array}$ & $1 \mathrm{C}-2 \mathrm{~A}$ & 4 \\
\hline \multirow{3}{*}{$\triangle \longrightarrow \nabla$} & \multirow{3}{*}{$\begin{array}{l}\text { Type } 3 \text { girder precedes Type } 4 \text { girder with SS lag } \\
\text { time }\end{array}$} & $2 A-2 B$ & 8 \\
\hline & & $3 A-3 B$ & 3 \\
\hline & & $4 A-4 B$ & 10 \\
\hline \multirow{2}{*}{$\triangle \triangle$} & \multirow{2}{*}{$\begin{array}{l}\text { Type } 3 \text { girder precedes another Type } 3 \text { girder with } \\
\text { SS lag time }\end{array}$} & $2 C-3 A$ & 8 \\
\hline & & $3 C-4 A$ & 4 \\
\hline \multirow{3}{*}{$\nabla \rightarrow \triangle$} & \multirow{3}{*}{$\begin{array}{l}\text { Type } 4 \text { girder precedes Type } 3 \text { girder with SS lag } \\
\text { time }\end{array}$} & $2 B-2 C$ & 6 \\
\hline & & $3 B-3 C$ & 10 \\
\hline & & $4 \mathrm{~B}-4 \mathrm{C}$ & 3 \\
\hline$\triangle \longrightarrow 0$ & $\begin{array}{l}\text { Type } 3 \text { girder precedes Type } 1 \text { girder with SS lag } \\
\text { time }\end{array}$ & $4 C-5 A$ & 8 \\
\hline
\end{tabular}

The SS lag refers to the amount of time whereby the fabrication of a successor girder type is required to be delayed with respect to the start event on the predecessor girder type, which varies dependent on the girder type combination in relation with the SS lag definition. It is seen from Table 4, under each particular girder type combination, different instances of the SS relationship between consecutive girders are associated with distinct lag time. For example, as for the girder type combination of Type 3 girder preceding Type 4 girder, SS lag time is 8 days, 3 days, and 10 days respectively, on the three particular instances identified in the case study (they are 2A-2B; 3A-3B; 4A-4B). Given girders of similar types, shop fabrication duration and start-to-start lags between consecutive girders show broad variations.

In short, the variations in time duration required to process the identical steel girders at a bridge girder shop are characterized and quantified based on a valid simulation model of the fabrication shop operations. It is noteworthy that given a particular sequence of construction in the field, the finish time of each girder fabrication needs to be predicted, which is critical input to plan (1) shipment and just-in-time (JIT) delivery of bridge girders on-site and (2) field crew installation. The objective of the JIT philosophy in lean manufacturing is to reduce and ultimately eradicate 'muda' waste (time spent and space used with non-value added). In the construction industry, this waste exists in terms of resource idling or waiting, excessive storing inventory, or unnecessary materials moving and handling (Ballard and Howell 1997). Applying sufficient buffers in time and space between fabricators and contractors might shield the project manager from the immediate impact of early or late deliveries of fabricated components. However, this can be expensive and practically infeasible; more important, such solutions are against the lean principles. As demonstrated in the present case study, the proactive solution is to directly 
address the root causes of variations in order to materialize project objectives in regards to cost efficiency, productivity, and lean production. Therefore, more effective modelbased variations assessment tools (such as SDESA utilized in the present research) are particularly instrumental in the revelation of these sources of variations, potentially leading to a highly predictable, more productive, and leaner system of bridge girder fabrication and installation.

\section{CONCLUSIONS}

This paper resorts a simulation case of planning bridge girder fabrication at a steel fabrication shop to illuminate on ' $m u r a$ ' inherent in girder fabrication. It is noteworthy these variations exist in reality, are clearly specified in the production plan, and exert significant influence upon time duration in making a girder and the lag time between the start times of processing consecutive girders at the fabrication shop. The impact of such variations cannot be overlooked or avoided in project planning and scheduling; instead, they need to be identified first and analytically modeled to assess their impact on shop scheduling. This study extended the application of a bridge girder fabrication simulation model, which had been developed for a bridge girder fabrication shop of our industry partner. We make an attempt to elaborate variations in girder fabrication time and intergirder lag in the context of applying lean concepts for planning bridge construction operations in practice. An in-depth analysis of the simulation model reveals the ' mura' inherent in girder design and fabrication processes, which is especially instrumental in planning lean processes for girder shipment, storage, and installation in the field aimed at minimizing the 'muda' waste such as renting extra laydown yard in the field or idling installation crew in the field due to waiting for girder delivery. This study explores a new lean approach to project planning and scheduling assisted with production operations planning by simulation. More effective model-based variations assessment tools (such as SDESA utilized in the present research) are particularly instrumental in the revelation of these sources of variations, potentially leading to a highly predictable, more productive, and leaner system of bridge girder fabrication and installation.

\section{ACKNOWLEDGMENTS}

The research was funded by the National Science and Engineering Research Council (NSERC), and Supreme Group through a Collaborative Research and Development grant (CRDPJ-501012-16). Kevin Guile, Ken Bird, David Fritz, and Chris Ritcey of Supreme Group are acknowledged for their supporting and facilitating the research.

\section{REFERENCES}

Adams, J., Balas, E., and Zawack, D. 1988. "The shifting bottleneck procedure for job shop scheduling.” Management Science, 34(3):391-401.

Arisha, A., Young, P., and El Baradie, M. 2001. "Job Shop Scheduling Problem: an Overview." In Proceedings of the International Conference for Flexible Automation and Intelligent Manufacturing (FAIM 01), Dublin, Ireland, July", pp. 682-693.

Aziz, R. F., and Hafez, S. M. 2013. "Applying lean thinking in construction and performance improvement." Alexandria Engineering Journal, 52(4), 679-695.

Baccarini, D. 1996. "The concept of project complexity-a review." International Journal of Project Management, 14(4), 201-204. 
Ballard, G., and Howell, G. 1997. "Toward construction JIT." In Proceedings of the 1995 ARMCOM conference, Association of researchers in construction management, Sheffield, UK.

Dosumu, O. S., and Aigbavboa, C. O. 2017. "Impact of Design Errors on Variation Cost of Selected Building Project in Nigeria." Procedia Engineering, 196, 847-856.

Hasan, M., Lu, M., and Ritcey, C. 2019. "Simulation Based Approach to Systematic Project Planning and Scheduling at a Bridge Fabrication Shop" In Proceedings of the 2019 Winter Simulation Conference (WSC), National Harbor, MD, USA, 2019, pp. 3019-3030, doi: 10.1109/WSC40007.2019.9004918.

Ibbs, W. 2012. "Construction Change: Likelihood, Severity, and Impact on Productivity." Journal of Legal Affairs and Dispute Resolution in Engineering and Construction, 4(3), 67-73.

Lawler, E.L., Lenstra, J.K., and Kan, A.H.G. Rinnooy. 1982. "Recent developments in deterministic sequencing and scheduling: A survey.” In: Dempster, M.A.H., Lenstra, J.K., Kan, A.H.G. Rinnooy (Eds.), Deterministic and Stochastic Scheduling, Reidel, Dordrecht. pp. 35-73.

Lu, M., and Wong, L.C. 2007. "Comparison of two simulation methodologies in modeling construction systems: Manufacturing-oriented PROMODEL vs. construction-oriented SDESA." Automation in Construction, 16: 86-95.

Liu, J., and Lu, M. 2018. "Constraint Programming Approach to Optimizing Project Schedules under Material Logistics and Crew Availability Constraints." Journal of Construction Engineering and Management, 144(7), 04018049.

Ortega, I., and Bisgaard, S. 2002. "Quality improvement in the construction industry: three systematic approaches." Total Quality Management, 11 (4-6), 383-392.

Pidd, M. (1998). "Computer Simulation in Management Science”. New York: Wiley, Chichester.

Sacks, R., and Goldin, M. 2007. "Lean Management Model for Construction of HighRise Apartment Buildings." Journal of Construction Engineering

and Management, 133(5), 374-384.

Shingo, S., and Dillon, A. 1989. "A study of the Toyota production system from an industrial engineering viewpoint." Portland, OR: Productivity Press. ISBN 0-91529917-8. OCLC 19740349.

Song, L., and Abourizk, S.M. 2003. "Building a virtual shop for steel fabrication." In Proceedings of the 2003 Winter Simulation Conference. 2003, 1510-1517(3).

Tommelein, I. D. 1997. "Discrete-Event Simulation of Lean Construction Processes." In Proceedings of the 5th Annual Conference of the International Group for Lean Construction. Gold Coast, Australia, 16-17 Jul 1997. pp 121-136.

Tzortzopoulos, P., and Formoso, C. T. 1999. "Considerations on Application of Lean Construction Principles to Design Management." In Proceedings of the 7th Annual Conference of the International Group for Lean Construction. Berkeley, USA, 26-28 Jul 1999. pp 335-344.

Womack, J. P., and Jones, D. T. 1997. "Lean Thinking-Banish Waste and Create Wealth in your Corporation." Journal of the Operational Research Society, 48(11), 11481148. 
Lean Construction Planning subject to Variations in detailed Features of Fabricated Bridge Girders

This page was intentionally left blank. 